\title{
Políticas del espectro de John Cage: su obra musical a través de Jacques Derrida
}

\section{John Cage's spectrum politics: his musical work through Jacques Derrida}

\section{Gustavo Celedón Bórquez ${ }^{1}$}

${ }^{1}$ Universidad de Valparaíso, Valparaíso, Chile

gustavo.celedon@uv.cl

\section{Resumo:}

En una aproximación filosófica al trabajo del compositor estadounidense John Cage, se aplican las nociones derrideanas de espectro y fantasma para comprender su concepción del sonido y revelar la condición política de su arte. Esta condición está absolutamente ligada a un deseo de justicia que nace en las raíces de una América devastada por el dominio europeo. Su manifestación, en la obra de Cage, es la intervención y el desarme de la música occidental. De esta manera, el trabajo artístico, según John Cage, está siempre arraigado a un trabajo político cuyo horizonte es la justicia, horizonte que, en efecto, Jacques Derrida ha puesto como condición de todo hacer.

Palabras-clave: obra política de John Cage; espectro; nativos norteamericanos; justicia; deconstrucción

\section{Abstract:}

In a philosophical approach to the work of North-American composer John Cage, we use Derridean's notions of ghost and spectrum for understanding his conception of sound and revealing the political status of his art. This condition is absolutely linked to a desire for justice that emerges in the roots of an America devastated by European dominance. Its manifestation in Cage's work is the intervention and the disarmament of Western music. 
Thus, artwork for John Cage is always rooted in a political work which horizon is justice. A horizon that Jacques Derrida puts as a basic condition for all doing.

Keywords: John Cage's political work; specter; American natives; justice; deconstruction

Data de recebimento: 03/10/2014

Data de aprovação final: 19/09/2015

"Ghost in the machine” (The Police, 1981)

\section{1 - Introducción}

No es extraño que el desarrollo del pensamiento y las necesidades de la investigación filosófica extiendan su inquietud al trabajo artístico. Tal extensión, en éste y en muchos casos, no responde necesariamente a los requerimientos y a la estructura de una ciencia estética; más bien, se inserta dentro de una búsqueda constante por reconocer lugares que, operando filosóficamente, se elaboran fuera de los límites de la disciplina filosófica o de la filosofía propiamente tal.

Es en esta línea que el presente artículo se introduce en la obra del artista y músico estadounidense John Cage. Su trabajo es, principalmente a través de la composición musical (fue también, aunque en menor grado, artista plástico y escritor), un radical cuestionamiento a la tradición occidental.

Gran parte de sus biógrafos estadounidenses han querido ver en él un espíritu que sería propio de EE.UU.: el de la invención y la reinvención, la partida desde cero, la autoconstrucción de un pueblo y de un poder en la lejanía y en la independencia de Europa. Es el caso, por ejemplo, de la biografía Begin Again realizada por SILVERMAN (2010), cuyo eje central se corresponde a esta idea. 
A John Cage, para quien la historia no constituye ningún deber de facto (CAGE, 2003, p.39), tales ideas no le son ajenas salvo por, punto importante, su fuerte y progresivo descontento por las políticas que se apoderaban, desde su país, del mundo entero. En este sentido, su temprana sentencia "Latinoamérica es la tierra del futuro" (CAGE, 1970, p.45) es totalmente significativa, puesto que, en el seno de una nación cuya libertad no ha sido sino el principio de propiedad - los Estados Unidos -, uno de sus más creativos e interesantes ciudadanos comprendía que el ejercicio artístico/político no sólo debía traspasar las fronteras de su país, sino que, en general, debía constituirse según la idea de traspasar todo aquello que es y se parece a una frontera.

\section{2 - John Cage: política de espectros}

John Cage es sin duda uno de los compositores más célebres e importantes del siglo XX. Indexado dentro de la vanguardia y catalogado como experimental, su obra es de alguna manera indiferente a estas nominaciones y su interés estuvo siempre impulsado por el deseo de desarmar lo que para él era el núcleo de la música occidental y que, con el dodecafonismo de Schönberg, se acentuaba e incrementaba: la relación entre los sonidos - y no los sonidos mismos. Este gesto, revolucionario, no sólo se inscribió como un gesto meramente estético, sino que aspiró siempre a traspasar los límites del arte para extenderse a todos lados, no otra cosa que para aportar, de manera cierta y comprometida, a una revolución general.

Heiner Müller es un dramaturgo alemán, quizás el más importante, en el siglo XX, luego de Bertolt Brecht. En el documental dirigido por Henning LOHNER (1993) en tributo a John Cage, The revenge of the dead indians, dice lo siguiente:

Cage es la venganza del indio muerto contra la música europea /.../ En realidad la historia [de EE.UU.] está compuesta por los Indios muertos, a causa del rechazo del subconsciente. Y esto sucede siempre así. La cultura que triunfa es la de los vencidos, no la de los vencedores. La cultura de los vencidos, incluso los vencidos muertos, se infiltra en aquella de los vencedores y la influye, determinándola y cambiándola. Eso es muy interesante. Es la indianidad de Cage. 
Las palabras de Heiner Müller subrayan la dimensión política de una obra criticada a veces de ser no-política. Dice CAGE (2003, p.298): "La gente critica frecuentemente mi obra por no ser política. Yo no estoy interesado por la política de poder. Lo que me interesa es el uso de la inteligencia y la solución de problemas imposibles”.

Suponemos entonces, a partir de estas palabras, que el trabajo de John Cage es un trabajo político. Ciertas indicaciones, por otro lado, insisten en ello. Tres máximas operativas que aquí rescatamos:

a) En primer lugar, máxima de Cage, la disolución de las fronteras entre el arte y la vida. Dice Marc DACHY (2000, p.15):

\begin{abstract}
El arte es el prototipo de la transformación del mundo y de nosotros mismos. Tal es la enseñanza que desarrolla John Cage a través de una práctica libre del arte, es decir, a través de la invención de procedimientos creativos nuevos y de modelos de libertad, a través de una obra musical que abre a la percepción del sonido, al gozo puro del arte y de la vida misma /.../ A las regresiones, a las depresiones intelectuales y artísticas siempre prontas a 'clasificar' las vanguardias como un fenómeno quizás exaltante, sino pasado, Cage opone el 'fenómeno futuro', liberar al hombre, reevaluar integralmente sus percepciones, es decir, sus interpretaciones. Se trata de prolongar el trabajo del arte moderno y de invertir una situación de hecho - el confinamiento del arte en los registros de la estética o del divertimento - y, desarrollando el rol de la estética como la invención de conceptos de obras, de instituir de nuevo el arte como un campo de experimentación a partir del cual cambiar el mundo.
\end{abstract}

b) Más allá incluso del trabajo musical, lo más importante es mejorar el mundo: "Mis ideas parten ciertamente en el campo de la música. Tal campo, por así decirlo, es un juego de niños [...] Nuestro trabajo correcto ahora, si amamos la humanidad y el mundo en que vivimos, es la revolución” (CAGE, 1967, p.ix).

c) Lo que efectivamente se propone Cage, es la construcción de una experiencia más amplia del espíritu: "Llegué a la conclusión de que inicialmente se trataba de producir una revolución del espíritu (mind), y yo diría ahora que esto debería ser o idealmente debería ser, aunque esté aún escéptico a este tema, una revolución de la sociedad” (CAGE, 2003, p.282)

La dimensión política de su trabajo no se constituye ni alrededor de intereses ni en relación a las necesidades de la representación. En principio, ella pretende construir sus propias 
maneras, su propia entrada, actuar en otro espacio, introducir una nueva dimensión. Dice nuevamente Heiner Müller en el mismo film (LOHNER, 1993):

\begin{abstract}
Allá [en Estados Unidos], tuve la primera vez un deseo, una necesidad de paisajes. Paisajes cuya extensión y cuyas dimensiones fuesen de tal manera que no pudiesen ser domesticables, catalogables. Hice entonces un crucero en el Delta del Misisipi, un crucero totalmente normal. Instalaciones de perforaciones petroleras, plantaciones, la mitad podrida, la mitad hundida en los pantanos. Y después el presentimiento de cocodrilos presentimiento más que realidad -, hacía todo muy agradable. El capitalismo tenía también sus márgenes. Espacios que no manejaba enteramente. Y es simplemente magnífico que existan márgenes, pues los márgenes rompen las fronteras. Y para mí lo esencial del trabajo de Cage ha sido el franquear incansablemente las fronteras. Más allá, encontramos un terreno desconocido y este desconocido estimula la curiosidad y la creatividad.
\end{abstract}

En efecto, la inquietud - o la curiosidad - es para Cage el motor de su arte a la vez que el motor de su impulso político. No es sino en la curiosidad del traspaso, en la experimentación de lo incalculable, donde el espíritu encuentra una suerte de espacio y se da el tiempo para, en estricto rigor, salir. Defínase en pocas palabras han dicho a Cage: "sal de la caja [cage] en la que te encuentres" (CAGE, 2003, p.303). Salir no a un lugar esperado, sino, por el contrario, a un lugar inesperado, al menos en alguno de sus puntos. Sólo esa podría ser la máxima de una experimentación: "Lo que pasa es que yo me transformé en un auditor y la música se ha transformado en algo a escuchar" (CAGE, 1973, p.7-8). Así, la cuestión es traspasar las fronteras para arribar a lugares desconocidos desde los cuales, múltiples, las fronteras serán visualizadas como mero azar: “¿Cuál es la naturaleza de una música experimental? Es simplemente una acción cuyo resultado no está previsto" (CAGE, 1973, p.69).

La venganza de los indios muertos adquiere esa faceta: la relativización de los límites, la necesidad volcada al azar, el trazo que cae. Todo aquí conjuga para nuestro análisis: una venganza de indios, de indios muertos, es la venida o el arribo de fantasmas, de espectros. Y un espectro es, para el filósofo francés nacido en Argelia, Jacques Derrida, aquello que no se da jamás en la forma de la presencia, la disyunción en la presencia misma del presente: "Un espectro parece presentarse, luego de una visitación. Nos lo representamos pero no está presente, él mismo, en carne y hueso" (DERRIDA, 1993, p.166). 
Esta no-nitidez o no-delimitación de los espectros es proporcional a las fronteras que se desarman con John Cage, cuya música será, de una parte, una música de la no-presencia, de lo no-presente, es decir, una música que no se limita a los márgenes de la música, de la música tradicional y sus reglas, sino que, por el contrario, se extiende más allá de estos límites, perdiendo la capacidad de otorgar un indicativo para señalarla, esto es, para consolidarla presente. Revolución de la música que no es sino revolución del espíritu, de la sociedad. Dice DERRIDA (1993, p.184):

\begin{abstract}
Intempestivo, "desencajado" (out of joint), incluso y sobre todo si parece venir a su hora, el espíritu de la revolución es fantástico y anacrónico de principio a fin. Él debe serlo - y entre todas las cuestiones que nos asigna este discurso, una de las más necesarias concerniría sin duda a la articulación de estos conceptos indisociables y que deben, sino identificarse, al menos pasar el uno sobre el otro sin atravesar ninguna frontera conceptual rigurosa: espíritu de revolución, realidad efectiva (productiva o reproductiva), espectro.
\end{abstract}

Fantástico, es decir, según su raíz, fantasmagórico a la vez que anacrónico, con un tiempo que le es propio pero, a la vez, de siempre, de los espectros, de la muerte de aquellos que devendrán espectros, aquí los indios. Así, la revolución no es suya, de Cage, pues la revolución es sin propiedad. Esto es, sin sujeto. La revolución es la venida de los espectros, su conjuro positivo, la aparición, la llegada de los sonidos, de los ruidos, de la anarquía de los sonidos. Pero no se trata, sin embargo, de la figura del indio como representante natural de la anarquía sonora, como si ella le perteneciese en vida, sino del conjuro del indio muerto bajo la forma del desarme de la música occidental, desarme que en Cage se produce precisamente a través de la solicitud de la libertad sonora.

Derrida juega, a lo largo del texto Spectres de Marx, con los términos disjonction (disyunción), inyuction (inyunción) y conjoction (conjunción):

a) El conjuro (conjuration) deriva de esta última. Disyunción es lo propio del tiempo: tiempo disyunto, que no es la época, el presente, sino el tiempo mismo que se separa o se desencaja con respecto a sí mismo (DERRIDA, 1993, p.129). No en su momento histórico, sino él mismo, él mismo siendo disyunto, no otra cosa que la injusticia, como traduciría Nietzsche a Anaximandro y seguiría Heidegger: “Injusticia sería la des-juntura [disjointure] o el desyuntamiento [disjointement]" (DERRIDA, 1993, p.54). 
b) La conjunción es el intento por comprender la justicia como unión y harmonía. De esta manera, lo hace Heidegger: "Heidegger interpreta Diké como juntura [jointure], ensamblaje [ajointement], ajustamiento [ajustement], articulación del acuerdo o de la harmonía" (DERRIDA, 1993, p.19),

c) En medio de esta doble significación que sitúa lo justo de lo injusto, Derrida habla de la inyunción a propósito de Marx, de esa inyunción que aspira a reunir sin reunión, a conjuntar sin conjunción, es decir, a mantener la disyunción conjunta en su disyunción: "La inyunción misma (que nos dice siempre elegir y decidir de acuerdo a aquello que heredas) no puede ser una sino dividiéndose, deseando, difiriendo ella misma, hablando a la vez varias veces" (DERRIDA, 1993, p.40).

Y agregamos las siguientes palabras de DERRIDA (1993, p.58):

Se nos pide (prescribe, quizás) volvernos, nosotros, al porvenir, juntarnos en este nosotros, ahí donde la disparidad se vuelve a ese singular juntar, sin concepto ni seguro de determinación, sin saber, sin o antes de la junción sintética de la conjunción o de la disyunción. La alianza de un re-juntar sin conjunto, sin organización, sin partido, sin nación, sin Estado, sin propiedad.

Es este, finalmente, el sentido del conjuro: "Se trata, en efecto, de convocar tanto espíritus como espectros en el gesto de una conjuración positiva, aquella que jura para llamar y no para reprimir" (DERRIDA, 1993, p.176-177), "para hacerles justicia” (DERRIDA, 1993, p.277). Se conjura a los fantasmas que, prescribiendo una orden sin orden, transitan y devuelven lo justo en la disyunción, a la disyunción, por la disyunción. Invocar a los fantasmas, liberar los espectros. Justamente, es ésta conjunción disyunta lo que vuelve difuso los límites y las fronteras, lo que es de lo que no es, siendo y no siendo, característica fundamental, hemos visto, del espectro.

Inyunción que conjunta manteniendo la disyunción a través del conjuro, la música de John Cage, sin organización, sin partido, sin Estado y sin propiedad, estaría al servicio de los indios muertos, espectros que vienen a corroer, en nombre de la justicia que persiste e insiste, la música europea. 
En este sentido, el aspecto político de la obra de John Cage adquiere la forma de una actividad. Dicha actividad es clara: traspasar las fronteras para un ensanchamiento del espíritu a través del conjuro positivo. De acuerdo a esto, lo importante será observar cómo el trabajo musical de John Cage, tal como él se realiza, produce o pretende producir una revolución. En definitiva, qué es lo que se inscribe en el arte de John Cage que, no diferenciándose de la vida, permitiría este ensanchamiento y esta revolución del espíritu a través del conjuro de espectros.

\section{3 - John Cage: máquina de arte}

El poeta norteamericano David Antin ha comentado el texto Composition as a process (CAGE, 1973, p.18-51), en un libro que tomamos en su traducción francesa, “john cage sans cage", esto es, “john cage sin caja”, pero también "john cage sin John Cage”, sin él mismo, sin el sujeto, el individuo, el nombre e, importante, sin su discurso, sin sus palabras. Dice ANTIN (2011, p.35):

Cuando pienso en este texto / me parece más útil considerar su estructura como la organización de su función y de preguntarse cómo este texto funciona / lo que pienso es que podemos responder que funciona como una máquina de arte / ¿qué es una máquina de arte? / Una máquina de arte es un sistema cuyas partes una vez que se han puesto en marcha, actúan las unas sobre las otras de tal manera que hacen que veas las cosas de manera diferente.

En primer lugar, Antin subraya lo importante: Composition as a process, célebre texto de John Cage, en donde, entre otras cosas, se explicitan sus nociones de forma, material, método y estructura, queda comprendido como una máquina, como una máquina de arte, en un doble sentido:

a) Es una máquina de arte el texto mismo, tal como está escrito

b) Es una máquina de arte la composición musical de John Cage 
En efecto, se trata aquí de una cuestión de funcionamiento y de puesta en marcha. Pues la composición de Cage funciona regularmente como una composición de elementos que se introducen en un procesador que expulsa resultados insólitos. Este espíritu maquínico en relación inmediata a su deseo de revolución del espíritu, queda tempranamente marcado. Su pieza Bacchanale (1940), que inaugura el piano preparado, a saber, aquel piano intervenido con clavos, gomas y otros elementos entre sus cuerdas, no es otra cosa que una pregunta por y una demanda a la máquina, su cuestionamiento a través de ella misma, cuyo vigor es el espíritu mismo expuesto a lo inesperado: Cage incita al piano, en efecto, a transformarse en un productor de inesperados.

Por otro lado, nos encontramos con su también célebre texto The future of music: Credo, escrito en1937 y publicado en 1958, ahí donde la juntura entre tecnología y revolución de la música y construcción de un mundo mejor, quedan vinculados para siempre. Escribe CAGE $(1973$, p.6):

\begin{abstract}
Antes que esto pase [revolución radical de la música], centros de música experimental deben ser establecidos. En ellos, los nuevos materiales, osciladores, tornamesas, generadores, medios para amplificar pequeños sonidos, fonógrafos cinematográficos, etc., disponibles para su uso. Los compositores trabajarán con medios del siglo XX para hacer música. Performances de los resultados. Organización del sonido para propósitos extramusicales (teatro, danza, radio, cine).
\end{abstract}

No obstante, lo primordial aquí es lo siguiente: aquello que es una máquina de arte para David Antin, es la estructura musical en John Cage. En efecto, la afirmación de la máquina de arte concluye toda una reflexión sobre la división del todo en partes, esto es, sobre la definición de estructura que nos da $\operatorname{CAGE}(1973$, p.16). El asunto pasa por hacer que la máquina no repose en su habitualidad, que no quede presa en una función determinada que a la vez la determine. La máquina, así, adquiere un toque de inmaterialidad. Dicho de otro modo, funciona de alguna manera en contra suya, revelando un acontecer que reproduce en el instante. Escribe CAGE (1973, p.2-3):

La mayoría de los inventores de instrumentos musicales eléctricos han intentado imitar los instrumentos del siglo XVIII y XIX, tal como en un principio los diseñadores de automóviles copiaron el carruaje. El Novachord y el Solovox son ejemplos de este deseo de imitar el pasado en vez de construir un futuro. Cuando Theremin proporcionó un 
instrumento de genuinas nuevas posibilidades los Thereministas hicieron el mayor esfuerzo por sonar como un viejo instrumento, dándole un dulce vibrato asqueroso, y ejecutando en él, con dificultad, obras maestras del pasado. Aunque el instrumento es capaz de una vasta variedad de cualidades sonoras, obtenidas por el giro de un dial, Thereministas actúan como censores, dándole al público los sonidos que éstos desean. Estamos vetados a nuevas experiencias sonoras.

De ahí que la maquinicidad de John Cage no repose inmediatamente en el instrumento, sino más bien en un modo de disponer: la máquina no es sólo una máquina, sino una máquina de arte, esto es, su programación emancipadora, productora de cambio. No reposa en el objeto - en el destino - del aparato, sino en la disposición de éste para ensanchar el espíritu.

Es en este sentido que David Antin nos dice que una máquina de arte es aquella máquina que nos hace ver las cosas de manera diferente. Creemos, no obstante, que lo que está en juego es más radical.

En efecto, tal "ver las cosas de manera diferente" no corresponde a una máquina de opiniones y es aquí necesario retomar una vez más la figura de Jacques Derrida para introducirnos en la profundidad de una diferencia, a fin de comprender que aquí no se trata simplemente de puntos de vista sobre las cosas. Se trata más bien de una máquina poseída por la diferencia, por una alteridad radical. El piano preparado, por ejemplo, no es jamás una máquina de puntos de vista. Es el mismo piano diferenciándose de sí mismo, evidenciando un cambio, permitiendo la aparición de sonidos inesperados, es decir, de diferencias no notificadas. Esto produce ciertamente un quiebre: el sistema tonal de diferencias es puesto en problemas al entrar en relación con sonidos que no poseen de antemano el correlato de sus posiciones, distancias y frecuencias. Lo que ahí se revela es la incertidumbre de un "apareciente" que, en el tiempo mismo de su aparición, es incodificable.

La red de diferencias queda entonces intervenida por relaciones con las cuales no se cuenta, y las diferencias mismas se diluyen en una alteridad mayor. En este sentido, la diferencia que el auditor - incluido el compositor y el intérprete - experimenta, no se inscribe en un sistema conocido: diferencias tonales, distinciones de volumen, etc. Por el contrario, quien oye queda expuesto a una efectiva tentativa de disolución de cualquier sistema diferencial y, por lo tanto, medianamente impedido de cualquier distinción. La diferencia ha roto la diferencia. 
Pues una diferencia (différence), dice Derrida, en el horizonte de una real justicia, es en verdad una "différance", con esta $a$ que ha querido introducir el filosofo para marcar una diferencia inaudible, una diferencia en la diferencia. Dos extractos de "La Différance" que pueden dar cuenta de esto. El primero, para insistir que si esta máquina de arte nos hace ver las cosas de manera diferente, tal diferencia habría de ser considerada siempre "más allá". Escribe DERRIDA (1972, p.14)

\footnotetext{
Este movimiento (activo) de la différance sin origen, ¿no podría haberse llamado, simplemente y sin neografismo, diferenciación? Entre otras confusiones, tal palabra habría dejado pensar en alguna unidad orgánica, originaria y homogénea, que viene eventualmente a dividirse, a recibir la diferencia como un acontecimiento. Sobre todo, formada sobre el verbo diferenciar, anularía la significación económica del rodeo, del plazo temporizador, del 'diferir'.
}

En el segundo extracto, remarca DERRIDA (1972, p.5): "Es inaudible la diferencia entre dos fonemas, aquello único que les permite a estos ser y operar como tales". Ahora, bien, esta diferencia, inaudible, ¿no es acaso un silencio?

Frecuentemente se dice de John Cage el músico e incluso el filósofo del silencio. Es el adjetivo más común para comprender su música, considerando que, precisamente, su obra más célebre es 4'33" (1953), obra compuesta a partir de puros silencios. Motivado por los White Paintings (1951) de su amigo Robert Rauschenberg, serie de cuadros blancos, con leves variaciones, Cage decide componer la pieza. Tomando por material el silencio y recurriendo a operaciones por azar - Cage compone la pieza a través de tiradas del Tarot (FETTERMAN, 1996, p.70) -, la pieza queda finalmente constituida por tres partes, cada una, repetimos, hecha de puro silencio. Las duraciones respectivas son de 30", 2'23", y 1'40'.

Son varios los motivos y los análisis que vienen a hacerse cargo de esta pieza. En principio, su duración es una crítica a la música envasada, a la música comercial. Pero es el advenimiento sin planificación de los sonidos llamados ambientales lo que constituye uno de los aportes más importantes de la obra, el cual se corresponde, sin duda, a la idea cageana de dejar los sonidos ser ellos mismos y permitirles ser escuchados. John Cage retira la cobertura musical o al menos la reduce a sus propios bordes, realizando un corte espacio-temporal en 
donde las formas y las relaciones entre los elementos, entre los sonidos y los ruidos indiferenciándose, son convidadas a silenciarse para dejar aparecer, en primer lugar, a estos ruidos y a estos sonidos que se encuentran por todas partes, apareciendo sin los caprichos y sin las filtraciones de la música que, en segundo lugar, desaparece para dejar aparecer el azar de toda aparición, de todo arribo sonoro. La conexión se borra.

De ahí que Cage revolucione la máquina, haciéndola girar de manera extraña: una máquina que no produce series ni en serie; una máquina que no produce encadenamientos al servicio de una lógica conectiva, sino una máquina que abre su mecanicidad a la producción y a la contemplación del azar, a la producción de una conectividad cuya función es borrarse cada vez. Una máquina que no es unidad orgánica productora de diferencias a partir de sí misma. Es como la différance derrideana, a saber, "una estructura de devolución generalizada" en donde el presente no es sino "traza (trace) y traza de la borradura de la traza" (DERRIDA, 1972, p.25).

Esta máquina que superpone silencios - 4'33” es al menos tres silencios - y que permitiría ver las cosas de manera diferente, es una máquina de la borradura, máquina de silencios que, estableciendo las diferencias, se retira para diferenciarse de las mismas, desentendiéndose de cualquier presente fijo. Este movimiento de retiro hacia una diferencia auroral u originaria, sin distinciones, es decir, ahí donde la diferencia está ella misma diferenciada, en un proceso de devoluciones infinitas, se corresponde al movimiento de una máquina compositiva que se diferencia de las relaciones establecidas por un sistema composicional como lo es la música: no son ya dos sonidos que se encuentran y cuyo encuentro es susceptible de ser referido y comprendido por un sistema diferencial de distinciones o relaciones - el dodecafonismo, por ejemplo -, sino dos sonidos que se diferencian en el silencio, cuyo campo de acción, a saber, una pieza musical - como lo es 4'33" - es finalmente la movilización o la nivelación y la desnivelación que se produce en el acontecer de esta multiplicidad de silencios. El silencio de John Cage será lo que la trace es para Jacques Derrida, planteándonos el arduo problema sobre la relación entre la imagen y el sonido, entre la trace y el silencio, ahí donde este último se separa de lo visual, imaginativo, representativo: el silencio es también el silencio de la imagen. Este problema, sin embargo, no es desarrollado en este artículo. 
“Y las marcas son algo así como la ocurrencia del sonido?” - preguntan a Cage. "¡Oh síl” - responde él (CAGE, 2003, p.198).

Por ello en el documental John Cage: musique au Bac de COMBES (2003), Pierre Boulez ironizará con la idea, referida a Cage, de aceleración y desaceleración del silencio. No llega a comprender que cada movimiento de 4'33" es una nueva experiencia del tiempo, una nueva época del silencio. Pasa que sólo aconteciendo, el silencio permite la obra, esto es, la puesta en escena de los sonidos - y los silencios mismos - según el azar, según el diseño o la forma que no logra imprimirse en ningún sistema de registros sino que, conectada a un movimiento maquínico de superposición de silencios, viene a acontecer sobre el silencio generalizado, a silbar en la profundidad de un no-decir.

\section{4 - John Cage: máquina de espectros}

Afirma Jacques Derrida en el film Ghost Dance de McMULLEN (1983): "Creo al contrario que el porvenir es de los fantasmas y que la tecnología moderna, de la imagen, de la cinematografía y de la telecomunicación realza el poder de los fantasmas, el retorno de los fantasmas".

Lo anterior desemboca en una reflexión sobre los espectros o en aquello que nos permitiremos llamar, finalmente y de manera más precisa, una máquina de espectros, conjuntando los términos y las ideas que hemos aquí convocado. Máquina de espectros donde el genitivo es doble: por una parte, esta máquina produce espectros y, por otra, está poseída por ellos.

Reinsertando el tema que nos convoca, la espectralidad del trabajo de John Cage y la relación a los nativos norteamericanos que Heiner Muller atribuía al compositor, nos remitimos a una de sus lecturas más importantes: Henry David Thoreau. Invadido por una re-lectura de 
Walden en 1958, el compositor descubre el amor del escritor por la discontinuidad de lo sonoro. Leemos en el texto de BOCK (2006, en línea)

Después de haber gastado muchas horas en la naturaleza, escuchando los sonidos de su medio ambiente, Thoreau se convence de que la música es para siempre y que sólo el escuchar es intermitente. En repetidas ocasiones habla de una corriente de sonido, una música ambiental infinita, sin principio ni fin. Al igual que Cage, Thoreau piensa que el mundo se llena de música, audible en cualquier momento dado.

Y, describiendo los ritos nativos, escribe THOREAU (2007, p.31-32):

Los perros siempre son elegidos para estas fiestas [ritos de los nativos norteamericanos]. Junto a las canciones, hay exhortaciones del hombre viejo - cada vez que el orador profería el nombre del Gran Espíritu, la audiencia responde kara-ho-ho-ho! La primera sílaba es proferida en un tono rápido y fuerte, y cada una de las 31 sílabas adicionales, débiles y más rápidas. Ellos dicen que el orador toca al Gran Espíritu cuando menciona su nombre, y que el efecto en la audiencia puede compararse a un soplo [golpe] sobre una cuerda tensa, la cual vibra de más a menos hasta restablecer la calma.

Al respecto, la música de los nativos norteamericanos posee, según LEVINE (1994, p.4) “una tangible conexión a la espiritualidad". Es el caso, por ejemplo, de los nativos Choctaw, del sudeste de los Estados Unidos, cuya música y danzas tribales se relacionan, hasta el día de hoy a conexiones con ancestros y espíritus: "Los cantantes Choctaw [...] dicen que en la mañana después de un buen canto, pueden oír las voces de sus ancestros cantando y bailando en los extensos campos de la danza abandonada" (LEVINE, 1994, p.4). Asimismo pasa con uno de los rituales más conocidos, el Ghost Dance (Danza Fantasma). Más reciente, en 1889, este ritual nace en el seno la Iglesia Nativa Americana (Native American Church) que oficialmente es reconocida recién en 1919. Afirma LINDSAY (1994, p.20):

El Ghost Dance se origina en 1889 a partir de la visión de un profeta Paiute conocido como Wovoka o Jack Wilson; la ceremonia se diseminó rápidamente entre los pueblos de la Gran Cuenca y del Area Llana. Wovoka enseñó que la práctica del Ghost Dance daría lugar a la resurrección de los indios muertos y reubicaría al bisonte en las planicies y praderas, permitiendo a los Nativos Americanos levantarse contra los Americanos Europeos y expulsarlos del continente.

Pero no es la música nativa lo que John Cage absorve o hereda. Se trata por el contrario de la desaparición forzada de los indios que, en el gesto político de la composición musical cageana, re-viene bajo la forma del desarme de la música occidental. Es en este sentido que la máquina de arte de John Cage puede inscribir su producción sonora en relación a una 
producción de espectros. Frente a la modernidad conquistadora, reproduce, con sus mismos artefactos, lo que ella necesita olvidar para siempre, reduciéndolo a cero: la aniquilación de la conquista. Es esto lo que los espectros de John Cage se adjudican: la destrucción de la modernidad no logra extenderse, sin embargo, a los fantasmas. Estos permanecen, vivos y muertos, acechando la tecnologización - la tecnocracia - de la sociedad moderna.

La producción de espectros tendrá entonces que explicar su proceder maquínico. Nos preguntamos entonces cuáles son los espectros o los fantasmas que la máquina de Cage viene a reproducir: los sonidos, los sonidos como espectros, ahí cuando la siguiente definición del espectro es totalmente aplicable al sonido: el espectro “deviene más bien 'algo' que permanece difícil de nombrar: ni alma ni cuerpo, y lo uno y lo otro” (DERRIDA, 1993, p.25).

La fantasmagoría en Cage funciona con la introducción en la obra de los sonidos-ruidos llamados externos. Ésta, la obra, es la puesta en escena de aquello que pretende ser escuchado en su integridad. Clara tendencia en música: precisar la escucha como escucha de una obra. Pero ésta, la obra, se somete con Cage a la acontecimientalidad del instante. Es requerida y complementada, llevada a un destino diferente, inesperado, por la inclusión de estos ruidos que la obra habría, inmersa en un contexto ideal, excluido. Escribe nuevamente DERRIDA (1993, p.31):

Repetición y primera vez, he aquí quizás la cuestión del acontecimiento como cuestión del fantasma [fantôme]: ¿qué es un fantasma? ¿qué es la efectividad de un fantasma o la presencia de un espectro, es decir, de aquello que parece permanecer a la vez inefectivo, virtual, inconsistente como un simulacro? ¿Hay, entre la cosa misma y su simulacro, una oposición que se mantenga? Repetición y primera vez pero también repetición y última $v e z$, pues la singularidad de toda primera vez es también una última vez. Cada vez, es el acontecimiento mismo, una primera y una última vez.

Pues bien, efectivamente se trata del acontecimiento, como ocurrencia en una única vez, siempre expuesta al arribo de los sonidos del momento, del instante, que conforman la ejecución de la pieza en una pura singularidad. El fantasma, fantôme, es comprendido por su arribo. De hecho, dos palabras con las cuales Derrida comprende el espectro: l'arrivant (el arribante) y le revenant (propiamente el "fantasma", pero también "el que vuelve a venir"). 
Ahora bien, la palabra francesa arriver tiene una doble connotación que pierde en español: arriver es "arribar", "llegar", pero también "ocurrir", "acontecer". "Ce qui arrive..." es aquello que llega, que viene y re-viene (o "reaparece", para seguir la traducción de José Miguel Alarcón y Cristina de Peretti de Spectres de Marx, Editorial Trotta) a la vez que es aquello que ocurre, que sucede, acontece. Afirma DERRIDA (1993, p.276)

Puesto que un fantasma [revenant] es siempre llamado a venir y revenir, el pensamiento del espectro [spectre], contrariamente a aquello que se cree de buen sentido, hace señal hacia el porvenir. Es un pensamiento del pasado, una herencia que no puede venir sino de aquello que no ha arribado aún - de lo arribante mismo.

Los sonidos-ruidos son los fantasmas tras las notas pulidas, tras las organizaciones complejas que la ciencia moderna ha producido y donado a la ciencia musical. Frente a su empaquetamiento, ellos vienen, revienen y ocurren. Acontecen, arriban. Lo que Cage deja expuesto es la ocurrencia a través del sonido, del sonido mismo que acontece, actividad, energía directa que ocurre en su indiferencia: no la organización ocurriendo, sino los sonidos. Fantasmas, reaparecidos que reaparecen alterando la máquina organizativa, el orden que se impone. Éste queda expuesto a su acoso, a la aparición repitente y constante, pero primera y última, de una región no-significada, habitada por estos espectros excluidos, esta materia sin forma, sin alma o estas almas sin materia. O lo uno y lo otro.

Cage es ya consciente, de alguna manera, y ya en la primera mitad del siglo $\mathrm{XX}$, que el avance y las intervenciones tecnológicas permiten la comunicación con los espectros, con los fantasmas, esto es, la posibilidad del arribo del azar, de la forma sin referente, sin logos: el azar toma posesión de la máquina. La máquina está poseída o el destino y la programación de esta máquina pierden el horizonte de su porvenir.

La acción fantasmal de la música de John Cage es la producción de escucha, el contacto con los sonidos que las capas organizativas una y otra vez cubren. Esto no pone al sonido en contacto con su "verdad", es decir, con un supuesto "ser-en-sí'. Es más bien la re-ubicación del ejercicio de la escucha en una dimensión donde el sonido se presenta en rebelión a su condición asignada de elemento de significación. Dicho de otra manera, la escucha se reencuentra ahora en conexión a sonidos que dejan de decir, que no se están sometiendo a una 
política del mensaje y, por tanto, que introducen a una relación con las cosas, aquí con los sonidos, que se despide de la comunicación o que reemplaza la comunicación por el conjuro. Es esta ausencia de la mediación comunicativa, por lo tanto, de la conversión de los acontecimientos en información, lo que produce una fuga espectral, un descontrol de la memoria y el desarme del Yo - en este caso, de la civilización que se instala en América a partir de la destrucción de su hábitat y habitantes.

Es así que el trabajo de Cage no consiste en una escucha dirigida al desciframiento de los sonidos. Estos se liberan. No de tal o cual mensaje a comunicar, sino de la comunicación misma. Al anular entonces la actividad del desciframiento, se pierde el control que ejerce la conversión de los acontecimientos en información, en datos, etc. El fantasma es ello: la imposibilidad extrema y finalmente nunca asible, de poder controlar.

Ante esto, nos remitimos al pensamiento de Nicolas Abraham y María Torok. Dice de ellos Derrida, en Ghost Dance del director McMULLEN (1983):

\begin{abstract}
Me interesé en cierta teorización que mis amigos psicoanalistas Nicolas Abraham y María Torok han elaborado a partir de Freud. La teoría del fantasma [fantôme] parte en efecto de la teoría del duelo. En un duelo normal, dice Freud, se interioriza la muerte, se toma la muerte sobre uno y se la asimila. Esta interiorización es una idealización: acoge la muerte. Mientras que en un duelo que no se desarrolla normalmente - un trabajo de duelo que no anda bien de alguna manera - no hay una verdadera interiorización. Hay lo que Nicolas Abraham y María Torok llaman una incorporación. Es decir, la muerte es tomada en nosotros pero no deviene parte de nosotros, ocupa un espacio particular en nuestro cuerpo. Puede hablar sola, acechar y 'ventrilocuar' nuestro propio cuerpo, nuestro propio discurso. Si bien el fantasma está encerrado en una cripta, en nosotros - somos una suerte de cementerio para el fantasma - el fantasma puede ser no sólo nuestro inconsciente sino, más precisamente, ser el inconsciente del otro. Es el inconsciente del otro el que habla en nuestro lugar. No es solamente nuestro inconsciente, sino el inconsciente del otro el que habla.
\end{abstract}

Se apunta aquí a una incorporación de la muerte que tiene como consecuencia un encriptamiento: la muerte no significada puede, como dice Derrida, ventrílocuar nuestro discurso, estando encriptada en nuestro cuerpo. Y se trata de un fantasma que de alguna manera atraviesa el inconsciente para habitar (en) el inconsciente del otro, abriendo una distancia infranqueable. Agrega DERRIDA (1976, p.42): 
Bien que las palabras 'fantasma' o 'acecho' se imponen a veces para designar a los habitantes de la cripta al interior del Yo (muertos vivientes como 'cuerpos extranjeros en el sujeto'), es necesario distinguir rigurosamente al extranjero incorporado en la cripta del Yo, del fantasma que viene a acechar desde el Inconsciente de un otro. El fantasma tiene su ocurrencia en el Inconsciente, no siendo el efecto de una represión 'propia' al sujeto que viene a acechar con toda suerte de ventriloquismos, sino 'propia' de un inconsciente parental. La re-venida no es un retorno de lo reprimido /.../ la cripta de donde re-viene el fantasma es la de un otro. Se podría decir que se trata de una exocríptica, de una heterocríptica. Esta heterocríptica llama a otra escucha que la incorporación críptica en el Yo.

Más allá del Yo y justo llegando a esta otra escucha, tan parecida a la nueva escucha que Cage busca - y así gran parte de la música experimental contemporánea -, el asunto se ubica detrás de la emisión del mensaje, por ejemplo, la emisión yoica, el yo proyectado. Así, en una composición. Así, en una declaración musical.

Y ni siquiera detrás de sí y dentro de sí, en el inconsciente. Inconsciente de otro, alteridad radical que trasciende el Yo y la forma del Yo, ha subrayado Derrida. Descifrar, tanto déchiffrer como décrypter, en francés, no es arrancar el mensaje. Es, en principio, y suponiendo que sea posible, entrar a la alteridad. Volver a la alteridad. Una apertura de la cripta no es sino la fuga, el dejar-salir-los-fantasmas como el dejar-ser-los-sonidos: movimiento incalculado que ubica en el presente una presencia fantasmal, que no se da a través de los códigos que supone el desciframiento de un tiempo dado.

El paso que hace John Cage a través de la composición musical, es el que va desde la juntura, por parte de la tradición musical europea, entre sonidos y significados, a la inyunción de sonidos y espectros: la música ya no está a favor de la civilización, sino de la justicia y la hermandad entre humanos, vivos y muertos, cuya convivencia trasciende, en la práctica, el aparataje comunicacional y las políticas de desciframiento para poder lograr acontecer en la apertura a una alteridad radical, como la de los nativos americanos frente a la abstracción civilizante. Todo ello implica una revolución y una reposición constante de formas, estructuras y métodos: máquina de arte, máquina de escucha. Comunión de espectros, la escucha, con John Cage, es en otra dimensión. Amor por todo lo que acontece, es una celebración de fantasmas, la danza ininterrumpida de los indios, de los desaparecidos, la actividad imperecedera, aquí a través del arte, de una justicia que jamás se rendirá. 


\section{Conclusión}

La indianidad de John Cage - afirmación de Heiner Muller - no hace referencia a ningún vínculo directo y consciente del compositor con los nativos norteamericanos. Se puede decir, en principio, que se trata de una metáfora que grafica una suerte de consecuencia justa (el desarme de la música occidental) frente a un acto injusto (la matanza de la población nativa norteamericana). Pero Muller va más allá y afirma la persistencia o la infiltración de los vencidos en el mundo de los vencedores. Son sus palabras, citadas en los primeros párrafos de este escrito. Deja así de ser un enunciado puramente metafórico para pasar al plano de lo inconsciente y, con mayor precisión, al plano de la justica en relación a lo inconsciente. Dicho de otro modo, Muller señala que un acto real de injusticia - situado e histórico - instala su proceso de ajusticiamiento en el plano inconsciente. La metáfora cede entonces no al plano psicoanalítico, como habría de pensarse, sino al plano deconstructivo, en tanto es ahí, en especial en la obra de Jacques Derrida, donde se ha pensado la justicia como re-venida del espectro. No ahondamos sin embargo en el diferimiento crítico que la deconstrucción efectúa respecto al psicoanálisis: no es éste nuestro tema. Más bien encontramos en las palabras con las cuales Heiner Muller define la música de John Cage, una materialización efectiva a las reflexiones que Derrida realiza a propósito del espectro y la justicia. En este sentido, abrimos un camino diferente para comprender el trabajo musical de John Cage en su carácter político, vinculándolo así al trabajo de la justicia y, en este caso, de la justicia en relación a los nativos norteamericanos.

Esta justicia se desarrolla a partir del desarme de una estructura o más bien de una normalidad occidental, a saber, la música. Este desarme no es en el vacío, ocurre sobre un espacio y tiempo que involucra injusticias, entre ellas, la violencia, muerte y desaparición de los indios nativos de Norteamérica. Es así que el desarme de la normalidad - de la estructura o normalidad musical y, con ellas, de la normalidad de escucha y, por tanto, finalmente, de la normalidad espiritual, sensible, mental - libera los espectros, abre la cripta (en términos de Torok y Abraham), introduce el desajuste. Y el desajuste o disyunción, hemos visto, es la 
forma misma de la justicia en tanto una normalidad no puede ser tal en la medida en que su formación ha sido sido injusta y violenta. En este sentido, la disyunción-desajuste es el ajuste mismo dentro de la normalidad sin memoria, de la normalidad que deja de escuchar.

Es así que la música de John Cage participa de esa justicia. Conjura los espectros involucrados, esto es, los espectros que han caído por la arremetida de la normalidad occidental-europea.

Podemos todavía preguntarnos por qué los nativos norteamericanos. La respuesta viene dada por la figura del inconsciente del otro que Derrida evocaba a propósito de Torok y Abraham. No son los indios muertos los que están en la consciencia y en el inconsciente de John Cage. Él mismo es poseído por una alteridad que no le es propia, por una alteridad que trasciende la generación misma de su formación inconsciente "personal” y que no logra depositarse en ninguna mente, en ningún espíritu particular, ni siquiera en un supuesto inconsciente colectivo estadounidense. La matanza de los nativos norteamericanos se convierte en una muerte inacabada que no deja de traspasar las mentes de sus habitantes - y más allá -, sin llegar a depositarse en ninguna de ellas, en ningún inconsciente particular o determinado. Por el contrario, la alteridad de inconsciente que propone Derrida es precisamente una "errancia" que adquiere la forma de algo que siempre re-viene, que siempre acecha, que no deja de venir y cuyo conjuro se produce a través de todo acto de disyunción, o, para decirlo derrideanamente, a través de la inyunción de una disyunción, tal cual la práctica musical de John Cage. De ahí que se trate de un espectro o fantasma que está vinculado a un acontecimiento verídico, la muerte de los nativos norteamericanos. Esto porque el fantasma siempre revendrá a partir de una muerte concreta, de una muerte acaecida, de una injusticia inscrita en la historia.

¿Habrán otros fantasmas en la música de John Cage? Probablemente. Sobre todo porque su música puede escucharse universalmente y reconocer, en la diversidad de territorios y de épocas, múltiples actos de violencia que habitan la memoria de pueblos y personas que pueden identificar sus muertos más próximos. Pero, por las mismas razones, los fantasmas que Heiner Muller identifica en la música del compositor son totalmente pertinentes. Después 
de todo, el esfuerzo de Jacques Derrida por pensar la justicia transita siempre entre la universalidad y la singularidad del espectro. Pues como dice en Force de loi: "Es necesario saber que esta justicia se dirige siempre a singularidades, a la singularidad del otro, a pesar o incluso en razón de su pretensión de universalidad" (DERRIDA, 2005, 44).

\section{Referencias}

1. ANTIN, D. (2011). john cage sans cage. París : Les presses du réel.

2. BOCK, J. (2006). "There is Music in Every Sound: Thoreau's Modernist Understanding of Music", COPAS, Vol. 7. En línea, extraído el 27 de agosto 2012 http://copas.uniregensburg.de/article/viewArticle/85/109

3. CAGE, J. (1967). A year from Monday. Connecticut: Wesleyan University Press,

4. CAGE, J. (1973), Silence. Conneticut: Wesleyan University Presse.

5. CAGE, J.; KOSTELANETZ, R. (2003). Conversing with Cage, New York: Routledge.

6. CAGE, J. (1970). “Other people think”. In: Kostelanetz, R. John Cage. Documentary Monographs in Modern Art, Connecticut: Praeger.

7. DACHY, M. (2000) "Introduction”. In : Cage, J. ; Kostelanetz, R. Conversations avec John Cage. París: Edition de Syrtes.

8. DERRIDA, J. (2005), Force de loi. París : Galilée.

9. DERRIDA, J. (1972). Marges de la Philosophie. París: Les Editions de Minuit.

10. DERRIDA, J. (1993). Spectres de Marx. L'état de la dette, le travail du deuil et la nouvelle Internationale. París: Galilée.

11. DERRIDA, J. (1976), "Fors”. In: Abraham, N.; Torok, M. Cryptonomie. Le Verbier de l'homme aux loups, Aubier: Flammarion.

12. FETTERMAN, W. (1996). John Cage theatre pieces: notations and performance. Amsterdam: Harwood Academic Publishers.

13. LEVINE, V. L. (1994). “American Indian musics, past and present”. In: Nichols, D. The Cambridge History of American Music. Cambridge: Cambridge University Press.

14. SILVERMAN, K. (2010) Begin Again. A biography of John Cage. New York: Knopf. 
15. THOREAU, H. D.; FLECK, R. (2007). Selections from The Indian Notebooks (1847

- 1861) of Henry D. Thoreau. Lincoln: The Thoreau Institute at Walden Woods.

\section{Filmes}

1. COMBES, G.; Bosseur, J-Y. (2003). John Cage : musique au bac. París: CNDP.

2. LOHNER, H. (1993). The Revenge of the Dead Indians: In Memoriam John Cage. New York: Mode Records.

3. MCMULLEN, K. (1983). Ghost Dance. Londres: Chanel Four Filmes.

\section{Discografía}

4. BERMAN, B. (1999) Cage: Sonatas and Interludes for Prepared Piano. Franklin: Naxos of America.

5. CAGE, J. (2008). Complete Prepared Piano. USA: Imports.

6. CAGE, J. (1951). Sonatas and Interludes for Prepared Piano Volume One. Hamburgo: Dial Records.

7. CAGE, J. (1951). Sonatas and Interludes for Prepared Piano Volume Two. Hamburgo: Dial Records.

8. THE POLICE. (1981). Ghost in the machine. Londres: A\&M Records.

9. ZAPPA, F. et al. (1993). A Chance operations. The John Cage tribute. New York: Koch Int'l Classics. 
Notas sobre el autor

Gustavo Celedón es investigador en Estética de la Universidad de Valparaíso. Es professor titular de la Escuela de Cine y miembro del claustro del Doctorado en Estudios Interdisciplinarios sobre Pensamiento, Cultura y Sociedad de la misma Universidad. Es Doctor en Filosofía por la Université Paris VIII - Vincennes-Saint-Denis y miembro del consejo científico del Laboratoire des Logiques Contemporaines de la Philosophie (LLCP) perteneciente a la misma casa de estudios. 